\title{
A Double-Function of PD-ECGF/TP Protein that Predict Response to Target Chemotherapy
}

Borzenko BG*, Bakurova EM and Mironova KA

Department of Biochemistry, Maksim Gorky National Medical University, Donetsk 83003, Ukraine

\begin{abstract}
High mortality rate of Ebola infections and less therapeutic options baffle the worldwide scientists and hamper the medical capability against disease spreads or disease-induced deaths and our understanding into this deadest virus. This article is to outline multi-facet factors of causing Ebola epidemics and further discuss several pathways to update present medical capabilities worldwide and solve this enigma forever.
\end{abstract}

\section{Introduction}

The intensity of cellular DNA synthesis and, thus, cell division, depends on the level of the deoxythymidine triphoshphate (dTTP), the key precursor for DNA synthesis). In human body dTTP is synthesized following one of the two possible pathways. They are both "de novo" synthesis from simple precursors: $\mathrm{NH}_{3}, \mathrm{CO}_{2}$, amino acids and "salvage pathway" from thymine and thymidine, create dTTP, which can be reincorporated into DNA. Thymidine phosphorylase (TP, EC 2.42.4.) is one from the key regulatory enzymes of "salvage pathway". TP first described in mammalian tissue in 1953 and then purified of plant, animal and bacterial sources [1,2]. This enzyme catalyses phosphorolysis of the nucleosidic linkage of pyrimidine-2-deoxynucleosides with the formation of the thymine and deoxyribose (Figure 1).

Numerous immunohistochemical and TP-enzyme activity studies have shown that TP participates in many pathological and nonpathological processes. In main metabolic function appears to be catabolic, although some bacteria and tumors utilize the reverse reaction anabolicaly under stress of certain genetic or dietary deficiency. The catabolic function of TP is also suggested that the enzymatic activity is inhibited by thymine and enhanced by thymidine. The biochemical characterization of TP demonstrated that the enzyme has a low

substrate specificity being able to recognize not only thymidine but also deoxypyrimidine [3] and some pyrimidine analogs [4-6]. Besides, resent studies have suggested, that TP plays a key role in maintaining the balance of the nucleoside pool and controlling nucleic acid gomeostasis, by ensuring the correct supply of deoxyribonucleoside triphosphates (dNTPs) for DNA replication and repair [7].

Various kinds of solid tumors express TP and high TP-activity is correlated with micro vessel density. A recent study has reported that TP enhances interleukin-8 (IL-8) expression [8] and various inflammatory cytokines, such as tumor necrosis factor $\alpha$ (TNF- $\alpha$ ) interleukin $1 \alpha(\mathrm{IL}-1 \alpha)$ and interferon $\gamma(\mathrm{IFN}-\gamma)$.

IFN- $\gamma$ most effectively increased the expression of TP in cultured human monocytic cells [9]. Nevertheless, how TP expression is upregulated in human tumors is still unclear.

In 1987 a novel angiogenic factor was investigated in platelet lysate [10], which was thought to be a classic growth factor, that binds its cell receptor to exert angiogenetic activity. This factor was named plateletderived endothelial cell growth factor (PD-ECGF). In 1992, during the characterization of different variants of PD-ECGF transcripts, Usaka and colleagues observed that the amino acid sequence of human PDECGF is homologues to that of E. coli thymidine physphorylase and reported, that PD-ECGF had additional structural and biochemical similarities with TP among which is TP activity [11]. Sequence analysis of the gene revealed a stretch of 120 amino acid to be identical to TP. Spraggon G. [12] based upon the already published three-dimensionalstructure of TP [13] and the biochemical and biophysical similarities between PD-ECGF and TP [14] suggested that human PD-ECGF was be same as human TP. How does TP induce angiogenesis? There are a lot of facts and a lot of hypothesis. It has been observed that TP strongly induces revascularization and plays an important role in angiogenesis, tumor growth, invasion and metastasis. Deoxy-D-ribose (DR) one of the degradation products of thymidine generated by TP activity has both angiogenic and chemotactic activity [15]. Both DR and TP inhibit a hypoxia-induced apoptotic pathway [16]. These findings suggest that DR is a downstream mediator of TP function. 2-deoxy-D-ribose, a stereoisomer of DR inhibits the promotion of angiogenesis, tumor growth and metastasis by TP $[17,18]$. Recent evidence suggests that DR effects endothelial cell migration though activation of the integrin downstream signaling pathway. It was known that DR may be an important energy source under hypoxic conditions. Many reports suggest that TP privotal for tumor progression [19].

\section{Conclusion}

In conclusion, PD-ECGF/TP has been found to have higher expression in tumor tissue compared to normal tissues in a variety of human malignancies and its expression is not only found in cancer cells but also in the stromal macrophages, lymphocytes and fibroblasts. Overall a higher level of PD-ECGF/TP expression is correlated with more metastasis and it appears to be a poor prognostic factor [21-24].

The disease in which an elevated of PD-ECGF/TP has been described thus far are immune system related and have features of chronic inflammation. Elevated levels of PD-ECGF/TP were found in rheumatoid arthritis patients. In another study it was shown that the expression of thymidine kinase (TK) and thymidine phosphorylase-TP as they relate to proliferation (Ki-67 labeling index) and angiogenesis

*Corresponding author: Borzenko BG, Department of Biochemistry, Maksim Gorky National Medical University, Donetsk 83003, Ukraine, Tel: 67-621-25-75; E-mail: borzenko.bg@rambler.ru

Received June 04, 2015; Accepted June 09, 2015; Published June 11, 2015

Citation: Borzenko BG, Bakurova EM, Mironova KA (2015) A Double-Function of PD-ECGF/TP Protein that Predict Response to Target Chemotherapy. Metabolomics 5: e136. doi:10.4172/2153-0769.1000e136

Copyright: (c) 2015 Borzenko BG et al. This is an open-access article distributed under the terms of the Creative Commons Attribution License, which permits unrestricted use, distribution, and reproduction in any medium, provided the original author and source are credited. 


Degraded DNA $\longrightarrow$ Thymidine

Figure 1: Phosphorolysis of the nucleosidic linkage of pyrimidine-2deoxynucleosides.

(CD-31-stained blood vessels) in a series of 110-small cell lung cancer (NSCLC) tumors. Tumor size was not found to be associated with TK, TP, Ki-67. These findings provide additional evidence for the role of thimidine metabolism in the complex interaction of proliferation and angiogenesis [22].

Recent studies have suggested that direct 5-Fluorouracil (FUra) anabolism to active Fur/UMP through the DNA pathway could result in high drug efficacy and demonstrated that TP was the limiting step of FUra tumoral activation following the DNA pathway yielding tumoral TP activity could therefore enhance drug response by augmenting the direct formation of the active metabolite Flu/UMP [23,24]. Since last century the 5-Fu with other anticancer agents and prodrugs from group of fluoropyrimidine are widely used. These drugs provide the basis for neoadjuvant chemotherapy in combination with various types of surgical

procedures and different methods of polychemotherapy (endolymphatic and intra-arterial chemotherapy). Although our results [24] and many reports from other laboratories suggest that $\mathrm{TP}$ is pivotal for tumor progression and may be used for diagnosis and treatment of oncology patients.

We have also provided that TP activity changes in the blood serum of patients with gastric cancer demonstrate their activity peculiarities in tissues. Thus far, we have not direct proof of the presence of isoenzyme forms of TP, but different localization in the cytosol and in the nucleus is known to be capable of isoenzymes. Our results raise the possibility that the control of individual dynamics of TP activity in blood serum of gastric cancer patients may be useful as information tool for monitoring of patients and treatment optimization [24].

Finally, TP can also play a role in chemotherapy, since it is involved in the metabolisation and degradation of several nucleoside analogs. In the light of the important role by TP activity both in tumor angiogenesis and in the synthesis of anticancer drugs, the ways for the discovery and the development of novel TP properties and inhibitors.

\section{References}

1. Friedkin M, Roberts $D$ (1954) The enzymatic synthesis of nucleosides thymidine phosphorylase in mammalian tissue. J Biol Chem 207: 245-256.

2. Focher F, Spadari S (2001) Thymidine phosphorylase: a Two-face Janus in anticancer chemotherapy. Curr Cancer Drug Targets 1: 141-153.

3. Desgranges C, Razaka G, Raband M, Bricand H (1981) Catabolism of thymidine in human blood platelets. Purification and properties of thymidine phosphorylase. Biochem Biophys Acta 654: 211-218.

4. Piper AA, Fox RM (1982) Biochemical basis for the differential sensitivity of human T- and B-lymphocyte lines to 5FU. Cancer Res 42: 3753-3760.

5. Desgranges C, Razaka G, Raband M (1983) Phosphorolysis of BVDU and other 5-substrated

6. 2-deoxyuridines by purified human thymidine phosphorylase and intact blood platelets. Biochem Pharmacol 32: 3583-3590.

7. Verri A, Focher F, Duncombe RI, Basnak I, Walker RT et al. (2000) Anti-herpes Vimplex virus activity of 4-thio-2-deoxyuridines: A. biological investigation for viral and cellular target-enzymes. Biochem J 351: 319-326.
8. Kornberg A, Baker T (1991) A DNA replication. Freeman and Co: New York.

9. Tabata S, Ikeda R, Yamamoto M, Furukawa T, Kuramoto T et al. (2012) Thymidine phosphorylase enhances reactive oxygen species generation and interleukin-8 expression in human cancer cells. Oncol Rep 38: 895-902.

10. Goto H, Kohno K, Sone S, Akiyama S, Kuwano M et al.(2001) Interferon gamma-dependent induction of thymidine phosphorylase platelete-derived endothelial growth factor through gamma-activated sequence - like element in human macrophages. Cancer Res 61: 469-473.

11. Miyazono K, Okabe T, Urabe A, Takaku F, Heldin CH (1987) Purification and properties of an endothelial cell growth factor from human platelets. $J$ Biol Chem 262: 4098-4103.

12. Usuki K, Saras J, Waltenberger J, Miyazono K, Pierce G (1992) Plateletderived endothelial cell growth factor has thymidine phosphorylase activity. Biochem Biophys Res Common 184: 1311-1316.

13. Spraggon G, Stuart D, Ponting C, Finnis C, Sleep D et al. (1995) Crystallysation and $\mathrm{x}$-ray diffraction of recombinant platelet-derived endothelial cell growth factor. J Mol Biol 234: 879-880.

14. Walter MR, Cook WJ, Brent Cole J (1992) Dimensional structure of thymidine phosphorylase from E.Coli and conformation of its phosphorylase activity. Biochem 31: 12141-12146.

15. Finnis C, Dodsworth N, Pollet CE, Carr G, Sleep D (1993) Thymidine phosphorylase activity of platelet-derived endothelial cell growth factor is responsible for endothelial cell mitogenicity. Eur J Biochem 212: 201-210.

16. Haraguchi M, Miyadera K, Uemura K, Sumizawa T, Furukawa T, et al. (1994) Angiogenic activity of enzyme. Nature. 368: 198

17. Kitazono M, Takebayashi Y, Ishitsuka K, Takao S, Tani A, et al. (1998) Prevention of hypoxia-induced apoptosis by the angiogenetic factor, thymidine phosphorylase. Biochem Biophys Res Commun. 253: 797-803.

18. Uchimiya H, Furukawa T, Okamoto M, Nakajima Y, Matsushita S et al. (2002) Suppression of thymidine phosphorylase-mediated angiogenesis and tumor growth by 2deoxy-L-ribose. Cancer Res 62: 2834-2839.

19. Nakajima Y, Gotanda T, Uchimiya H, Furukawa T, Haraguchi M, et al. (2004) Inhibition of metastasis of tumor cells overexpressing thymidine phosphorylase by 2-deoxy-L-ribose. Cancer Res 64: 1749-1801.

20. Akiyama S, Furukawa T, Sumizawa T, Takebayashi $Y$, Nakajima $Y$, et al. (2004) The role of thymidine phosphorylase an angiogenic enzyme in tumor progression. Cancer Sci 95: 851-857.

21. van Triest B, Pinedo HM, Blaauwgeers JL, van Diest PJ, Schoenmakers PS et al. (2000) Prognostic role of thymidylate synthase, thymidine phosphorylase/ platelet-derived endothelial cell growth factor and proliferation markers in colocteral cancer. Clin Cancer Res 6: 1063-1072.

22. Giatromanolaki A, Sivridis E, Maltezos E, Papazoglou D, Simopoulos C, et al. (2003) Hypoxia inducible factor 1-alpha and 2-alpha over expression in inflammatory bowel disease. J Clin Pathol 56: 209-213.

23. Brockenbrough JS, Morihara JK, Hawes SE, Stern JE, Rasey JS et al. (2009) Thymidine kinase and thymidine phosphorylase expression in NSCLC lung carcinoma and relation to angiogenesis and proliferation. J Histochem Cytochem 57: 1087-1097.

24. Ciccolini I, Cug P, Evrard A, Giacometti S, Pelegrin A et al. (2001) Combination of thymidine phosphorylase gene transfer and deoxyinosine treatment greatly enhances 5-FU antitumor activity in vitro and in vivo. Mol Cancer Ther 1: 133139.

25. Borzenko B, Bakurova E, Popovych Yi, et al. (2013) Activity of thymidilate "salvage pathway» enzymes in human gastric cancer and blood serum: correlation with treatment modalities. Exp Oncol 35:1-4. 